\title{
Explore the Factors That Influence and Mitigate Loss Aversion
}

\author{
Zixuan Ye
}

Department of Statistics Xiamen University, China

19020182203648@stu.xmu.edu.cn

\begin{abstract}
Loss aversion is another theoretical cornerstone of Kahneman and Tversky's prospect theor, which has been applied by behavioral economists in many fields such as consumption decisions, production/supply, investment[1]. Benartzi and Thaler first tried to explain the mystery of equity premium by using investors' loss aversion, and he focused on the impact of investors' investment performance evaluation period on investment returns[2]. Barberis combine traditional utility function and its prospect theory, suggests that due to the pain of loss to investors than equal comfort for investment returns, so investors must demand in order to avoid loss risk assets have higher expected return, on the contrary, because of risk-free bonds give investors with stable earnings, investors demand lower yields, Arjan discussed the optimal portfolio strategy for investors under loss aversion. Since the distribution of returns affects the explanatory power of loss aversion to the equity premium puzzle, Martin relaxed the assumption of independent and homogeneous distribution of returns in the model, and the application of a looser GARCH distribution supports the view that loss aversion can explain the equity premium puzzle[3]. Loss aversion is originally a branch of behavioral economics, which is widely used in all aspects of life and plays an important role in the overall industry design and planning. At the same time, this factor can be studied and discussed in the future. Finally, the above contents are summarized and analyzed to analyze the mitigating silver factors that may reduce the degree of loss aversion, and some suggestions and references are put forward for subsequent research.
\end{abstract}

Keywords: Loss aversion; Behavior of the economy; Affecting factors; Ease factor.

\section{INTRODUCTION}

Behavioral economics is as practical economics, which will be the root of the economic operation rule of the organic combination of science, psychology and economy, to discover current economics errors or omissions in the model, and then fix the mainstream economics on human's rational, self-interested, complete information, consistent lack of the basic assumptions of utility maximization and preference. Loss aversion in behavioral economics makes a lot of sense. Contrary to the standard assumption that only the final state affects choice, there is growing evidence that the carrier of utility is usually not the state,but rather the change with the reference point [5].

This paper examines both risk and risk-free loss aversion in to understand theboundaries of this seemingly universal phenomenon. Early evidence of loss aversion in a risk-free environment used coffee cups[6]. Participants were randomly assigned to sellers and buyers, with sellers getting a mug and buyers not getting a mug.Sellers were asked the minimum price they would be willing to pay to give up a cup, and buyers were asked the maximum price they would be willing to pay to buy a cup. On average, buyers were willing to pay no more than 2.87 , but sellers were asking 7.12. This difference could be explained by loss aversion to cups. The seller thinks the cup is a loss, and the buyer thinks the cup is a gain. In another condition of the experiment, the choosers were given the choice between receiving a cup or money. The average amount of money choosers needed to choose money over cups was 3.12 . This value is not reliably different from the price set by Buvers. As an example. Loss aversion has been implied in the premium of equity returns over bond returns[7]. It is worth noting that people do not think themselves or others are loss-averse (Fan Bowen).

A better understanding of loss aversion and its boundaries could have important implications for how managers and consumers operate in markets. Then 
review some previous studies on loss aversion and discuss some differences between the current experimental results and those reported by Bateman and colleagues [8]. This study also describe how to extend the endowment effect paradigm and propose several hypotheses that consider both risk and risk-free loss aversion, and the article will from the following dimensions to do a basic exploration on this question.

\section{FACTORS INFLUENCING LOSS AVERSION}

\subsection{Normalization of relationships}

previous researches about interpersonal relationships used norms of behavior to distinguish between two types of relationships: transactional and communal[16]. In exchange relationships, the main motivation for interacting with others is to get something from them: people care about what they get out of giving. People prefer to exchange an equal benefit for a given benefit the relationship is a quid pro quo. The interaction between strangers and business partners is a classic example of a quid pro quo relationship. In public relations, by contrast, the motivation to interact with others is to satisfy their needs because they are genuinely concerned with their well-being - people's views override the emphasis on self-interest. People prefer to receive benefits that are not comparable to those they give, because receiving different benefits shows they care about their own unique needs. Most family relationships and close friendships fall into this category. Recent marketing research points out that the relationship between consumers and brands often reflects interpersonal relationships in social contexts [9], and uses the norms of these relationships as a lens to evaluate brands and their behavior (Agarwal 2004). Recent research on the contextual effects of relational norms has found that these norms are used as guides even when there is no actual relationship to the object of evaluation [10]. What is important is that relationship norms are prominent at the time, even when product evaluations are carried out in unrelated situations. Following this line of research, the author carefully studied The Moderating Effect of Rela tionship Norm Salience on Consumer-s' Loss Aversion and proposed The significance of Relationship Norm as a situational variable to regulate people's Loss Aversion. Therefore, they examined the moderating effect of relationship name significance on consumer loss-aversion behavior in the literature they studied. In particular, They suggest that public relations naming makes consumers more loss-averse than exchange relationship naming, for two main reasons.

First, considering that the underlying intentions of consumers' interactions with their relationship partners are different in the two relationships, they suggest that relationship norms change consumers' cognitive perspectives, leading to possible differential treatment. Because the exchange relationship is a guiding principle, what is accepted is measured by what is given up. In the exchange relationship, people are more concerned about the net balance of input and result [16]. Previous research supports this premise, showing that trading thinking is associated with weaker endowment effects (Mande2002). However, matching a particular input to a subsequent result violates the norms of public relations. People avoid associating their Settings with what they give and do not calculate the net gain and loss. Thus, common norms will result in losses and gains (rather than being aggregated) being assessed, leading to consumer behavior consistent with stronger benefits Loss-averse Gree. Therefore, consistent with Ariely et al[12] on differences in cognitive perspectives and Novemsky and Kahneman on latent intention, the study believe that differences in consumer attention in the two relationships are the key mechanism by which relationship norms regulate consumer attention. Loss aversion second, Relationship norms may lead to differences in emotional attachment to the given object, leading to different feelings of loss between the two groups of consumers. In particular, public relations norms, relative to exchange norms, may influence the degree of perceived loss. When public relations norms are prominent, consumers view their relationship partners as close friends or family members.

Previous research pointed out that people in close relationships reinforce positive evaluations of their partners and greater commitment [13], in addition. People in committed relationships tend to have relatively low values for choices that threaten their existing relationships[14], believing that they will seek a higher relative value in order to break away from their current relationship partners. Consumers may show greater affection and commitment to their current choice, and thus greater resistance to abandoning it - indicating a relatively stronger degree of loss aversion. Further, it is found that confident bias leads to higher evaluations of work partners and colleagues [15] and the public norm is therefore more likely to lead to the giving of optiont(as friends or family) gradually becoming part of the consumer's self-extension [16], thereby enhancing the valuation. On the contrary. Trading norms suggest that the value assigned to an option will largely depend on the return it can earn. This suggests that, consistent with the view of the role of emotional attachment[17], the experience of losing oneself will be greater in public relations than in exchange relationships. The moderating effect of promoting relationship norms on consumer loss aversion. It is worth noting that the two factors differ in the cognitive perspective and emotional contribution to the overall moderating effect of the relationship between normative degree of consumer loss aversion and context. Researcher chose to be unable to distinguish the relative contributions of these two factors. Future studies can examine these two mechanisms separately through 
design studies in an attempt to isolate the individual weights of these contributing factors. In summary, when a relationship's norms stand out, it' s like any other environmental factor. Is to serve as a lens to guide people's subsequent behavior - in this case, to price a product without real value. There is a relationship between the consumer and the product.

\section{2 age}

According to the above experimental results, it is not difficult to find that older interviewees are more lossaverse. The researchers calculated the results as well as the linear regression of age,family financial experience, self-reported investment maturity and predicted loss aversion. The model includes three pseudo-coded study identifiers (study 2A, 2B, and 2C)[26]. Older individuals were more loss-averse than younger individuals. This association between age and loss aversion was present in all four studies. This study is quite necessary from a macro point of view, because it avoids repetition of samples to some extent and shows a certain correlation, which is quite rigorous[27].

\subsection{Education background, financial experience, investment experience}

Educated individuals had less loss aversion[22], $\mathrm{d}=$ 0.17, $95 \mathrm{CI}[-0.19,-0.15]$.[28] In addition,respondents with rich experience in family financial management have lower loss aversion than those with less experience in managing family financial management, and those who report higher investment maturity have lower loss aversion. The effects of these four surveys are listed separately. Also, whether loss aversion (risky investment choice)[29] is more correlated with relevant financial experience (involving investments)[30] than unrelated financial experience (especially paying bills). Investment-related household financial experience is associated with lower loss aversion and is similar in size to the small association between loss aversion and overall household financial experience. In contrast, household financial experiences related to bills were not associated with lower loss aversion. In other words, not all experiences are associated with loss aversion in the same way; Related experience in the same field (making financial investments) is more closely associated with investment choice loss aversion than unrelated experience (paying bills)[31]. As a robustness test, we separately examined alternative items that also seemed to assess relevant and unrelated experiences. Relevant financial experience consistently predicted lower loss aversion (mean correlation $=0.10$ ), while unrelated experience had a smaller mean effect (mean direct correlation $=-0.01$ )[32], resulting in poorer consistency.

In fact, this study is relatively reasonable. Subjectively, compared with normal people, people with educational, financial and investment experience have stronger risk control and tolerance, and they also have a relatively clear understanding of themselves. From an objective point of view, due to poor consistency, loss aversion is relatively small. In the case of higher educational background, financial experience and investment experience, loss aversion prediction is relatively low, which also provides a relatively complete proof of this problem.

\section{MITIGATING FACTORS FOR LOSS AVERSION}

Different theories predict that moderators differ significantly in interpreting the process of loss aversion[33]. Researchers have proposed a variety of explanations for loss aversion, including that it is driven by feelings of ownership, a tendency to consider losses prior to gains , tend to focus on loss over gain [34], confirmatory search and biashypothesis testing [35]. Some argue that loss aversion is rooted in a relatively stable psychological, physical, or physiological tendency to respond to loss more than gains [36].In addition, some investigations have psychologically questioned whether losses are greater than gains, or affective prediction error, in which people overestimate how much loss will affect how they feel[38]. These different interpretations of loss aversion lead to different predictions about how loss aversion can be tempered. Previous research on lossaverse moderators provides some support for many of these accounts. For example, studies supporting emotionbased explanations have found that loss aversion is greater when negative emotion is high, and aversion to hedonic goods is greater than aversion to utility goods.

Based on memory and preference construction, loss aversion is moderated by the order in which people consider gains and losses. People usually think about losses first; However, prompting people to think about gains first reduces loss aversion (Lohnson et al., 2007). Unlike many previous studies, we used a theory-driven approach to identify moderators, using a more representative sample, focusing on individual difference moderators rather than situational moderators, and repeating our results across several different samples and different measures of loss aversion.

First, since loss aversion is largely the result of constructed preferences, the people most susceptible to preference construction should be the least willing to lose. Studies of preference construction have repeatedly found that people with less knowledge, education, and experience(especially with particular attributes, domains, or product categories) are better able to construct their preferences than those with more domain knowledge and education. As a result, people with less domain knowledge, experience and education may be more reluctant to lose. Some previous studies have considered whether domain experience modulates loss aversion, 
although the results have been mixed. In the context of property ownership, some claim that investors are less averse to losses than apartment owners [39], while others have found no correlation between experience in the field and loss aversion (Bokhari Geltner, 2011). Other studies have shown that experienced dealers are less averse to losses than inexperienced dealers of trading cards and sports memorabilia. However, another paper in this area of research found that experienced stock and option traders had greater loss aversion than inexperienced stock and option traders (Haigh List, 2005). Pope and Schweitzer(2011) found that experienced professional golfers, including Tiger Woods, showed loss aversion when putting, but they did not compare the magnitude of loss aversion among experienced and less experienced individuals. Preference construction explanations also suggest that knowledge and experience about a particular attribute, product, or domain is more relevant than knowledge or experience about other domains (e.g., Hoeffler Ariely, 1999). For example, loss aversion is greater for hockey memorabilia than for football memorabilia, and the more knowledge about car safety features or the value of those features, the lower loss aversion is for car safety-related attributes. It is worth noting that several different explanations for loss aversion stem from memory, information processing, or attentional processes may produce the same prediction because people with more relevant knowledge and experience have well-structured knowledge and show less interference in retrieving knowledge, more adaptable to attention to information[40]. We also tested whether older people are more loss-averse than acquisitive people. Older individuals are more susceptible to primacy effect [41] and memory interference, they pay more attention to the first piece of in- formation or question considered and give greater weight to the first one. In the context of the endowment effect, this may mean that older sellers focus on the first information they consider, which is usually the value-added aspect thus, this may make them more averse to selling products and give more equal consideration to them than younger sellers who show a smaller primacy effect. In the context of loss-averse risk choice, this may mean that older people are less likely to fully consider loss and gain (value and opportunity per person), so they focus on the first aspect of consideration, the usual loss (for example, the aspect of valuediminishing gambling; Johnson et al.. 2007). There are other reasons why older individuals may be more lossaverse. Because older people tend to retain less specific knowledge. Advantages of detail, including price and probability, other things being equal, they may be more inclined to construct preferences than younger people. Unlike the preference construction theory of loss aversion, some other loss aversion theories, such as those based on emotion, seem to make the opposite prediction. These explanations may indicate that loss aversion decreases with age, since emotional regulation improves with age. Previous studies on age and loss aversion have yielded mixed results[42]. In these five samples, we examined whether age was associated with loss aversion. Although the nature of the survey prevented us from investigating the specific psychological processes underlying the relationship between age and loss aversion, we sought to rule out income effects, wealth effects, and other possible explanations.

\section{CONCLUSION}

Based on the literature of my research, this paper gives my views on the factors affecting loss aversion and their influence degree combined with the researcher's understanding. Based on the above observations, it is not difficult to see that when the total number of quantifiers in the study reaches a certain level, we can consider the design of the whole experiment as reasonable and fair, with certain explanatory significance. However, if the total number of experiments and research objects are not enough, this research can judge that it is ineffective. The analysis found that relationship norms, age, educational background, financial experience, and investment experience play a very important role in controlling such loss aversion, and their influence degree is also different. Similarly, this paper sorted out some possible mitigating factors for these influencing factors, and put forward the thinking of large sample test on this basis. Loss aversion may control the production and consumption of consumer goods. Although it is a simple psychological phenomenon, it plays an important role in production and life. If we understand loss aversion, we can understand the whole market.

\section{REFERENCES}

[1] Tversky and Kahneman.s Cognitive Illusions: Who Can Solve Them, and Why? Journal-[J]Frontiers in Psychology2021.

[2] The equity premium puzzle: new evidence on the optimal holding period and optimal asset allocation Journal- $[\mathrm{J}]$ Review of Behavioral FinanceVolume 8, Issue 1. 2016. PP 39-57.

[3] Robust Estimation for Poisson Integer-Valued GARCH Models Using a New Hybrid Loss

Journal of Systems Science and Complexity. 2021,34(04).

[4] Bateman, Ian, Daniel Kahneman, Alistair Munro, Chris Starmer,and Robert Sugden (in press),"Testing Competing Models of Loss Aversion: An Adversarial Collaboration," Journal of Public Economics, forthco.

[5] Becker, G.M., M.H. Degroot, and J. Marschak (1964), "Measuring Utility by a Single- 
Response Sequential Method," Behavioral Science, 9 (3), 226-32.

[6] Benartzi, Shlomo and Richard Thaler (1995), "Myopic Loss Aver-sion and the Equity Premium Puzzle," Quarterly Journal of Economics, 110 (February), 73.

[7] University of Pennsylvania; Shlomo Benartzi named Distinguished Senior Fellow at Behavior Change for Good Initiative Journal-[J]NewsRx Health and Science2018.

[8] Wicker, Frank, Douglas Hamman, Anastasia Hagen, Joy Lynn Reed, and James Wiehe (2001)," Studies of Loss Aversion and Perceived Necessity," The Journal of Psychology, 129 (1),75-89.

[9] Aaker, Jennifer, Susan Fournier, and S. Adam Brasel (2004),/When Good Brands Do Bad,Journal of Consumer Re-search, 31 (June), $10 \tilde{16 .}$

[10] Aarts, Henk and Ap Dijksterhuis (2003), /The Silence of the Library: Environment, Situational Norm, and Social Behavior,0Journal of Personality and Social Psychology, 84 (January),180̃28.

[11] Beggan, James K. (1992), /On the Social Nature of Nonsocial Perception: The Mere Ownership Effect,0Journal of Personality and Social Psychology, 62 (February), 229õ37.

[12] Belk, Russell W. (1988), /Possessions and the Extended Self,0Journal of Consumer Research, 15 (September), 1390̃68.

[13] Brookshire, David S. and Don L. Coursey (1987),/Measuring the Value of Public Good: An

Empirical Comparison of Elicitation Procedures,0American Economic Review, 77 (September), 5540̃66.

[14] Carmon, Ziv and Dan Ariely (2000), /Focusing on the Forgone: How Value Can Appear so Different to Buyers and Sellers,0Journal of Consumer Research, 27 (December), 3600̃70.

[15] Clark, Margaret S. (1986), /Evidence for the Effectiveness of Manipulations of Communal and Exchange Relationships,0Personality and Social Psychology Bulletin, 12 (December),4140̃25.

[16] Clark, Margaret S. and Judson Mills (1993), /The Difference between Communal and Exchange Relationships: What It Is and Is Not,OPersonality and Social Psychology Bulletin, 19(December), $6840 \tilde{9} 91$.

[17] Fiske, Alan P. (1992), /The Four Elementary Forms of Sociality: Framework for a Unified Theory of Social Relations,0Psychological Review, 99 (4), $6890 \tilde{0} 723$.
[18] Grayson, Kent and Tim Ambler (1999), /The Dark Side of Long-Term Relationships in Marketing Services,0Journal of Marketing Research, 36 (February), 1320̃41.

[19] Johnson, Dennis J. and Caryl E. Rusbult (1989), /Resisting Temptation: Devaluation of Alternative Partnersasa Means of Maintaining Commitmentin Close Relationships,Journal of Personality and Social Psychology, 57 (6), 967õ80.

[20] Loewenstein, George and Samuel Issacharoff (1994), /Source Dependence in the Valuation of Objects,Journal of Behavior Decision Making, 7 (September), 1570068

[21] Martz, John M., Julie Verette, Ximena B. Arriaga, Linda F. Slovik, Chante L. Cox, and Caryl E. Rusbult (1998), /Positive Illusion in Close Relationships,Personal Relationships, 5(2),1590̃81.

[22] The Moderating Effect of Relationship Norm Salience on Consumers.Loss Aversion

[23] Nayakankuppam, Dhananjay and Himanshu Mishra (2005), /The Endowment Effect: RoseTinted and Dark-Tinted Glasses,Journal of Consumer Research, 32 (December), 390005.

[24] Sen, Sankar and Eric J. Johnson (1997), /MerePossession Effects without Possession in Consumer Choice,Journal of Consumer Research, 24 (June), $1050 \tilde{17}$.

[25] Simonson, Itamar and Aimee Drolet (2004), /Anchoring Effects on Consumers.Willingness-toPay and Willingness-to-Accept,Journal of Consumer Research, 31 (December), 6810̃90.

[26] Thaler, Richard H. (1980), /Towards a Positive Theory of Consumer Choice,0Journal of Economic Behavior and Organization, 1 (March), 390060.

[27] Tversky, Amos and Daniel Kahneman (1992), /Advances in Prospect Theory: Cumulative Representation of Uncertainty,0Journal of Risk and Uncertainty, 5 (October), $297 \tilde{0} 323$.

[28] Watson, David, Lee A. Clark, and Auke Tellegen (1988), /Development and Validation of Brief Measures of Positive and Negative Affect: The PANAS Scales,0Journal of Personality and Social Psychology, 54 (June), 10630070.

[29] Burson, K., Faro, D., Rottenstreich, Y. (2013). Multiple unit holdings yield attenuated endowment effects. Management Science, 59, 5450̃555

[30] Abdellaoui, M., Bleichrodt, H., L'Haridon, O. (2008). Atractable method to measure utility and loss aversion under prospect theory. Journal of Risk and Uncertainty, 36, 2450̃266 
[31] Andrikogiannopoulou,A., Papakonstantinou, F.(2016).Heterogeneityinriskpreferences: Evidence from a real-world betting market. Swiss Finance Institute Research Paper No. 13-53.Retrieved from

[32] Arkes, H. (1991). Costs and benefits of judgment errors: Implications for debiasing. Psychological Bulletin, 110, $486 \tilde{4} 498$.

[33] Beggan, J. K. (1992). On the social nature of nonsocial perception: The mere ownership effect. Journal of Personality and Social Psychology, 62, 2290̃237

[34] Booij, A. S., Van de Kuilen, G. (2009). A parameterfree analysis of the utility of money for the general population under prospect theory. Journal of Economic Psychology, 30, 6510066.

[35] Carmon, Z., Ariely, D. (2000). Focusing on the forgone:How value can appear so different to buyers and sellers. Journal of Consumer Research, 27, 360 õ370.

[36] Cohen, J. (1992). A power primer. Psychological Bulletin,112, 1550̃159.

[37] Cumming, G., Fidler, F. (2009). Confidence intervals: Better answers to better questions.

Zeitschrift Fur Psy-chologie/Journal of Psychology, 217, 15 õ26.

[38] Haigh, M. S.,List, J. A. (2005). Do professional traders exhibit myopic loss aversion? An experimental analysis.The Journal of Finance, 60, 523õ534

[39] Harinck, F., Van Dijk, E., Van Beest, I., Mersmann, P. (2007). When gains loom larger than losses: Reversed loss aversion for small amounts of money. Psychological Science, 18,1099õ1105.

[40] Horowitz, J. K., McConnell, K. E. (2002). A review of WTA/WTP studies. Journal of Environmental Economics and Management, 44, $4260 \tilde{4} 47$.

[41] Lin, Q. C., Lee, J. (2004). Consumer information search when making investment decisions. Financial Services Review, 13, 3190̃333.

[42] Yechiam, E. (2018). Acceptable losses: The debatable origins of loss aversion. Psychological Research Psychologis che Forschung, 83, 1327001339. 